УДК 54.05

\title{
СУЛЬФАТИРОВАНИЕ БЕТУЛИНА ХЛОРСУЛЬФОНОВОЙ КИСЛОТОЙ В ДИОКСАНЕ И ДИМЕТИЛФОРМАМИДЕ
}

\author{
() В.А. Левданский ${ }^{1,2}$, А.В. Левданский ${ }^{1}$ Б.Н. Кузнецов ${ }^{1,2 *}$ \\ ${ }^{1}$ Институт химии и химической технологии СО РАН, ул. К. Маркса, 42, \\ Красноярск, 660049 (Россия), e-mail: inm@icct.ru \\ ${ }^{2}$ Сибирский феедеральный университет, пр. Свободный, 79, Красноярск, \\ 660041 (Россия)
}

\begin{abstract}
Установлено, что реакция сульфатирования бетулина хлорсульфоновой кислотой в диоксане или диметилформамиде протекает в гомогенной среде при температуре $40-60{ }^{\circ} \mathrm{C}$. Показано, что для полной этерификации бетулина до 3,28-дисульфата бетулина необходимо 4-5 ч. Дисульфат бетулина выделяют в виде натриевой соли.

Ключевые слова: бетулин, сульфатирование, хлорсульфоновая кислота, 1,4-диоксан, N,N-диметилформамид, 3,28-дисульфат бетулина.
\end{abstract}

\section{Введение}

В последнее время всевозрастающий интерес в медицине и фармацевтической промышленности проявляется к биологически активным веществам природного происхождения и медицинским препаратам, полученным на их основе. Соединениями, сочетающими в себе доступность с ценной биологической активностью богат класс тритерпенов [1]. Ярким представителем этого класса соединений, широко распространенным в природе, является бетулин (3ß,28-дигидрокси-20(29)-лупен). Содержание бетулина во внешнем слое коры березы - бересте - достигает 35\% [1]. Однако низкая растворимость бетулина и его производных в большинстве растворителей и нерастворимость в воде затрудняет их практическое использование и изучение биологической активности. Для придания растворимости бетулину и его производным используют различные методы химической модификации. Растворимость бетулиновой кислоты в воде обеспечивается солюбилизацией ее с помощью липосом [2]. Другой наиболее простой и эффективный способ придания водорастворимости бетулину и бетулиновой кислоте - это их сульфатирование с получением соответствующих сульфатов [3, 4].

Известно, что сернокислотные эфиры тритерпеноидов - бетулина, бетулиновой и олеановой кислот - проявляют высокую биологическую активность, являются ингибиторами комплемента. В работе [3] показано, что сульфатированные производные бетулина и бетулиновой кислоты проявляют более высокую биологическую активность как ингибиторы комплемента по сравнению с применяющимися в настоящее

Левданский Владимир Александрович - ведущий научный сотрудник, тел.: (391) 249-55-84, e-mail:inm@icct.ru

Левданский Александр Владимирович - научный сотрудник, тел.: (391) 249-55-84, e-mail:inm@icct.ru

Кузнечов Борис Николаевич - первый заместитель директора Института химии и химической технологии СО РАН, профессор, доктор химических наук, заведующий кафедрой аналитической и органической химии Сибирского федерального университета, тел.: (391) 249-48-94, e-mail: bnk@icct.ru, inm@icct.ru время медицинскими препаратами. Система комплемента является частью иммунной системы организма, которая активируется при попадании в организм чужеродных бактерий и антигенов. После уничтожения чужеродных тел активация комплимента прекращается.

Известные методы сульфатирования тритерпеноидов основаны на использовании серной кислоты и серного ангидрида. Сульфатирование бетулина

\footnotetext{
* Автор, с которым следует вести переписку.
} 
и бетулиновой кислоты серной кислотой проводят в пиридине в присутствии уксусного ангидрида [4]. В работе [5] исследовано сульфатирование олеаноловой и бетулиновой кислот комплексом серный ангидрид - диметилсульфоксид, полученным путем прибавления жидкого серного ангидрида к диметилсульфоксиду. Сульфатированные тритерпеноиды выделяют экстракцией хлороформом или бутанолом после разбавления реакционной массы водой и очищают методом колоночной хроматографии на силикагеле.

Сульфаты тритерпеноидов содержатся в некоторых растениях. Так, из листьев Schefflera Octophylla выделены и идентифицированы стереоизомеры сульфатов бетулиновой кислоты и сульфаты метилового эфира бетулиновой кислоты [6].

В настоящей работе впервые предложено проводить сульфатирование бетулина хлорсульфоновой кислотой в 1,4-диоксане или $\mathrm{N}, \mathrm{N}$-диметилформамиде.

\section{Экспериментальная часть}

ИК-спектры записаны на Фурье-ИК-спектрометре Vector-22 фирмы Bruker в области длин волн 400$4000 \mathrm{~cm}^{-1}$ в таблетках $\mathrm{KBr}$ (3 мг образца / 300 мг $\mathrm{KBr}$ ). Спектры ЯМР ${ }^{13} \mathrm{C}$ сняты на спектрометре Bruker Avance III 600 МГц в дейтерометаноле с привязкой к дейтериевому резонансу растворителя. Элементный анализ выполнен на элементном анализаторе Flash $\mathrm{EA}^{\mathrm{TM}}-1112$ (Thermo Quest Italia), одновременно определяющем количество (в \%) углерода, водорода и серы, а также кислорода.

Бетулин, используемый для сульфатирования, был получен по методике, приведенной в работе [7].

Растворители 1,4-диоксан, N,N-диметилформамид перед использованием были очищены и высушены известным методом [8].

Сульфатирование бетулина в N,N-диметилформамиде. В трехгорлую колбу объемом 100 мл, снабженную мешалкой, термометром и капельной воронкой, загружают 50 мл $\mathrm{N}, \mathrm{N}$-диметилформамида и при интенсивном перемешивании и охлаждении при температуре $-5-0{ }^{\circ} \mathrm{C}$ прибавляют по каплям 2 мл хлорсульфоновой кислоты. После того, как вся хлорсульфоновая кислота прибавлена, при перемешивании медленно порциями загружают 4,42 г (0,01 моль) бетулина, нагревают колбу на водяной бане до $60{ }^{\circ} \mathrm{C}$ и поддерживают эту температуру в течение 3 ч. Затем реакционную массу охлаждают до температуры $10-15^{\circ} \mathrm{C}$ и при перемешивании выливают в стакан, содержащий 100 мл 75\%-ного водно-этанольного раствора, содержащего 4\% гидроксида натрия. Наблюдается выпадение в осадок неорганической соли, ее отделяют фильтрованием, а оставшийся раствор концентрируют под вакуумом до полного удаления растворителя, получают дисульфат бетулина в виде натриевой соли и перекристаллизовывают из этанола. Выход продукта составляет 6,0 г (93\%).

Сульфатирование бетулина в 1,4-диоксане. В трехгорлую колбу объемом 100 мл, снабженную мешалкой, термометром и капельной воронкой, загружают 50 мл 1,4-диоксана и при интенсивном перемешивании и охлаждении при температуре $5{ }^{\circ} \mathrm{C}$ прибавляют по каплям 2 мл хлорсульфоновой кислоты. После того, как вся хлорсульфоновая кислота прибавлена, при перемешивании загружают 4,42 г (0,01 моль) бетулина, нагревают колбу на водяной бане до $40{ }^{\circ} \mathrm{C}$ и поддерживают эту температуру в течение 5 ч. Затем реакционную массу охлаждают до температуры $10-15^{\circ} \mathrm{C}$ и при перемешивании нейтрализуют до $\mathrm{pH} 7-8$, прибавляя 100-110 мл 75\%-ного водно-этанольного раствора, содержащего 4\% гидроксида натрия. Выпавшую в осадок неорганическую соль отделяют фильтрованием, а оставшийся раствор концентрируют под вакуумом до полного удаления растворителя и получают дисульфат бетулина в виде натриевой соли. Выход продукта составляет 6,2 г (96\%).

\section{Результаты и обсуждение}

Впервые предложено проводить сульфатирование бетулина хлорсульфоновой кислотой в 1,4-диоксане или $\mathrm{N}, \mathrm{N}$-диметилформамиде. При взаимодействии хлорсульфоновой кислоты с диоксаном или диметилформамидом образуется соответственно комплекс $\mathrm{SO}_{3}$ - диоксан или $\mathrm{SO}_{3}-$ ДМФА и выделяется $\mathrm{HCl}$ [9]:

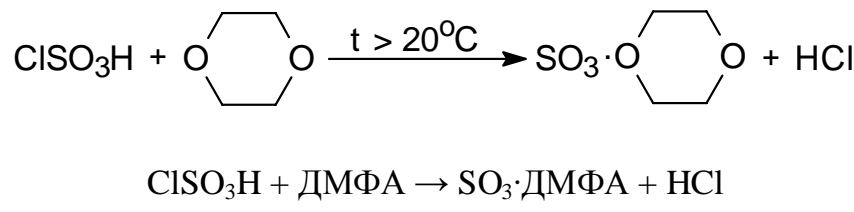


Реакция сульфатирования бетулина хлорсульфоновой кислотой в диоксане или диметилформамиде и последующее выделение 3,28-дисульфата бетулина в виде натриевой соли протекает по следующей схеме (рис. 1).

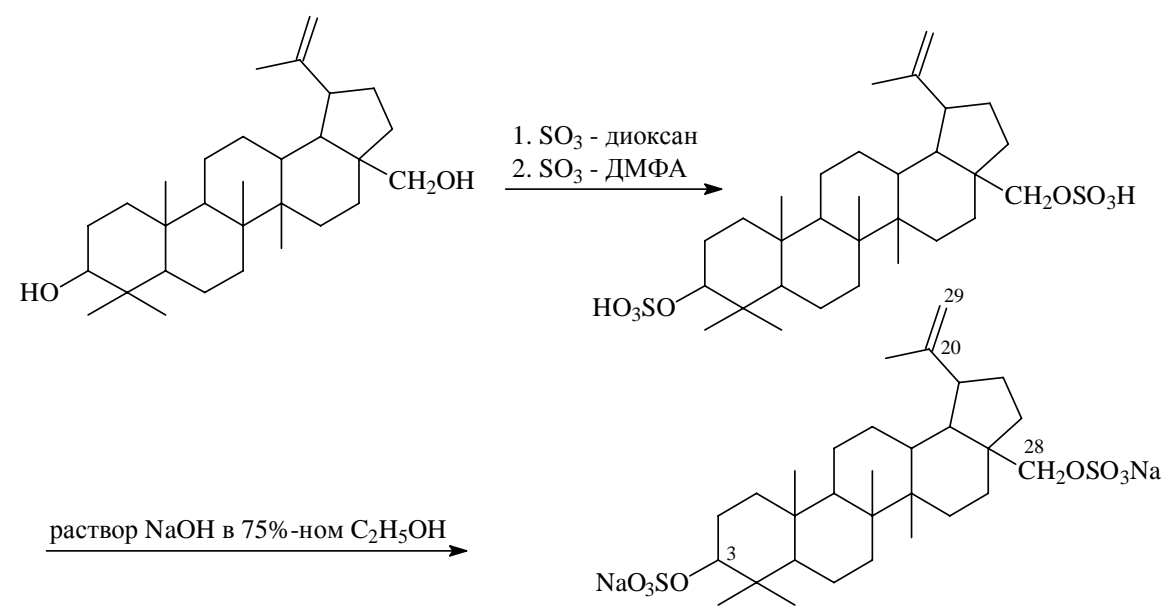

Рис. 1. Схема синтеза натриевой соли 3,28-дисульфата бетулина

Состав 3,28-дисульфата бетулина $\left(\mathrm{C}_{30} \mathrm{H}_{48} \mathrm{O}_{8} \mathrm{~S}_{2} \mathrm{Na}_{2}\right)$, полученного сульфатированием хлорсульфоновой кислотой в диоксане и диметилформамиде, подтвержден элементным анализом, строением ИК- и ЯМР ${ }^{13} \mathrm{C}$-спектрами. В ИК-спектре 3,28-дисульфата бетулина присутствуют полосы поглощения в области 834$835 \mathrm{~cm}^{-1}$ (SO) и 1221-1223 cмㄹ $\left(\mathrm{SO}_{2}\right)$, которые подтверждают введение сульфатной группы в молекулу бетулина (рис. 2).

ЯМР ${ }^{13} \mathrm{C}$-спектр бетулина достаточно подробно изучен. Известно, что химический сдвиг у вторичного атома углерода $\mathrm{C}_{3}$, связанного с гидроксильной группой, наблюдается при 78-79 м.д., а у первичного атома $\mathrm{C}_{28}$ при 59-60 м.д. [10]. На рисунке 2 приведен ЯMP ${ }^{13} \mathrm{C}$-спектр бетулина, а на рисунке 3 - ЯMP ${ }^{13} \mathrm{C}$ спектр 3,28-дисульфата бетулина.

Анализ ЯМР ${ }^{13} \mathrm{C}$-спектров (рис. 3,4 ) исходного бетулина и 3,28-дисульфата бетулина показал, что у исходного бетулина химический сдвиг атома углерода $\mathrm{C}_{3}$ наблюдается при 78,253 м.д. и атома углерода $\mathrm{C}_{28}$ при 58,963 м.д., после замещения гидроксильных групп на сульфогруппы химический сдвиг атома углерода $\mathrm{C}_{3}$ полностью сместился к 86,226 м.д., а атом углерода $\mathrm{C}_{28}-$ к 65,916 м.д. Это доказывает, что произошло полное замещение гидроксильных групп бетулина на сульфогруппы.

Из-за невысокой термостабильности комплекса $\mathrm{SO}_{3}$ - диоксан сульфатирование бетулина в диоксане осуществляют при температуре $40-50{ }^{\circ} \mathrm{C}$ в течение 4-5 ч, а в более стабильном в диметилформамиде комплексе $\mathrm{SO}_{3}$ - ДМФА - при температуре $60-80{ }^{\circ} \mathrm{C}$ в течение 2-3 ч.

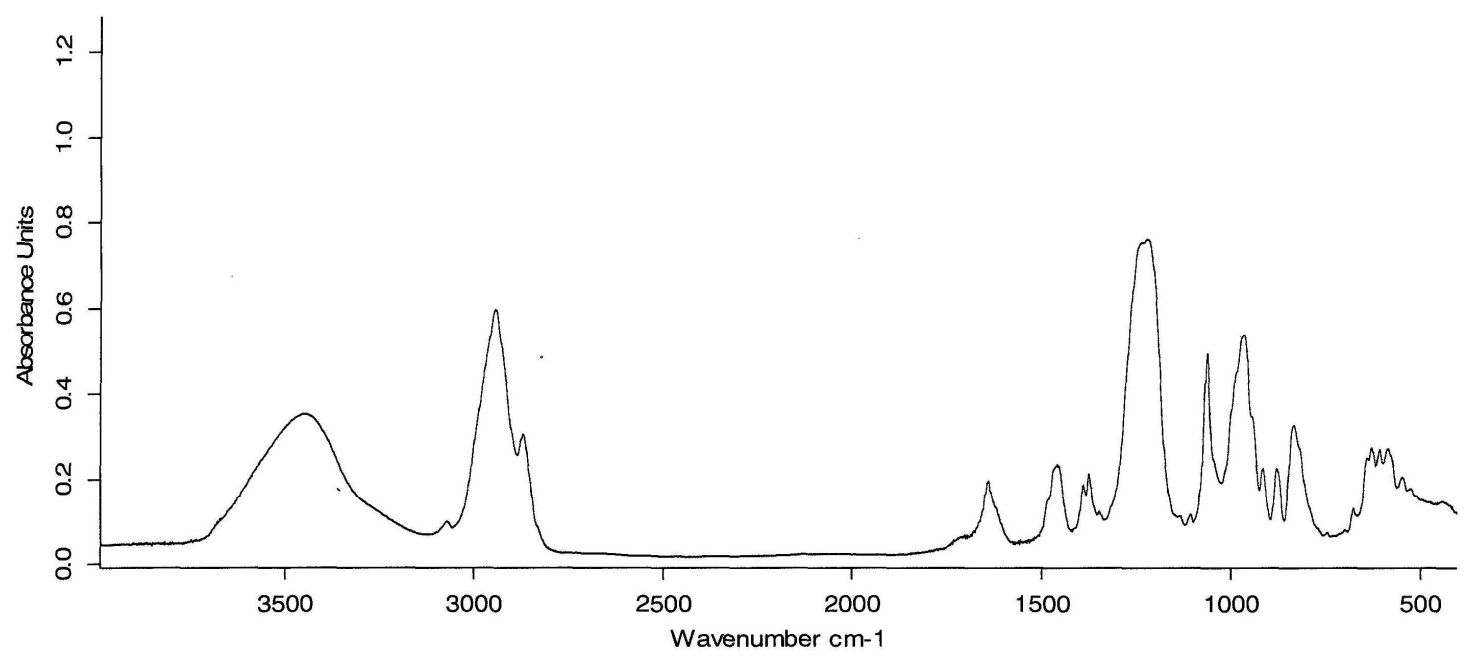

Рис. 2. ИК-спектр 3,28-дисульфата бетулина 


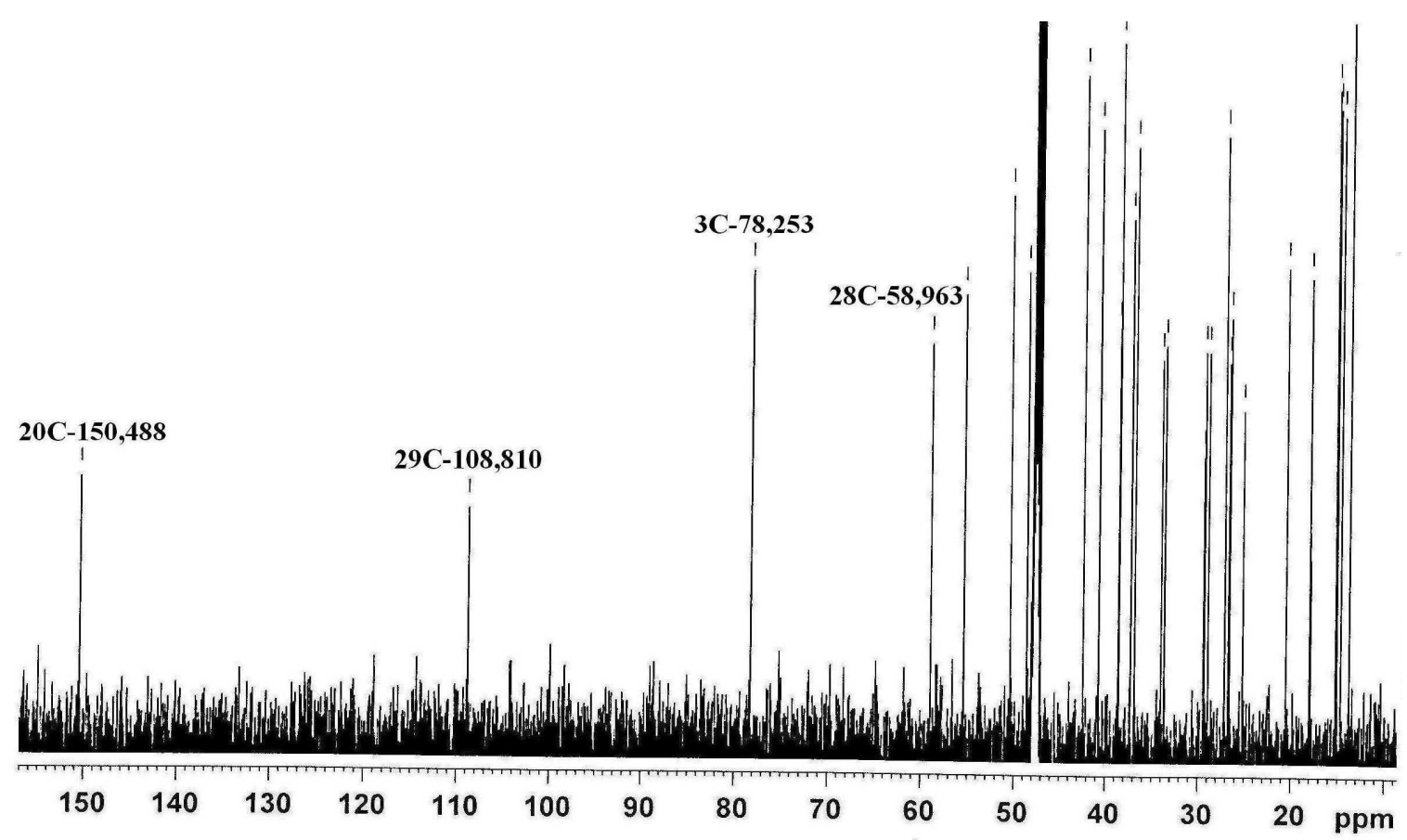

Рис. 3. ЯМР ${ }^{13} \mathrm{C}$-спектр бетулина

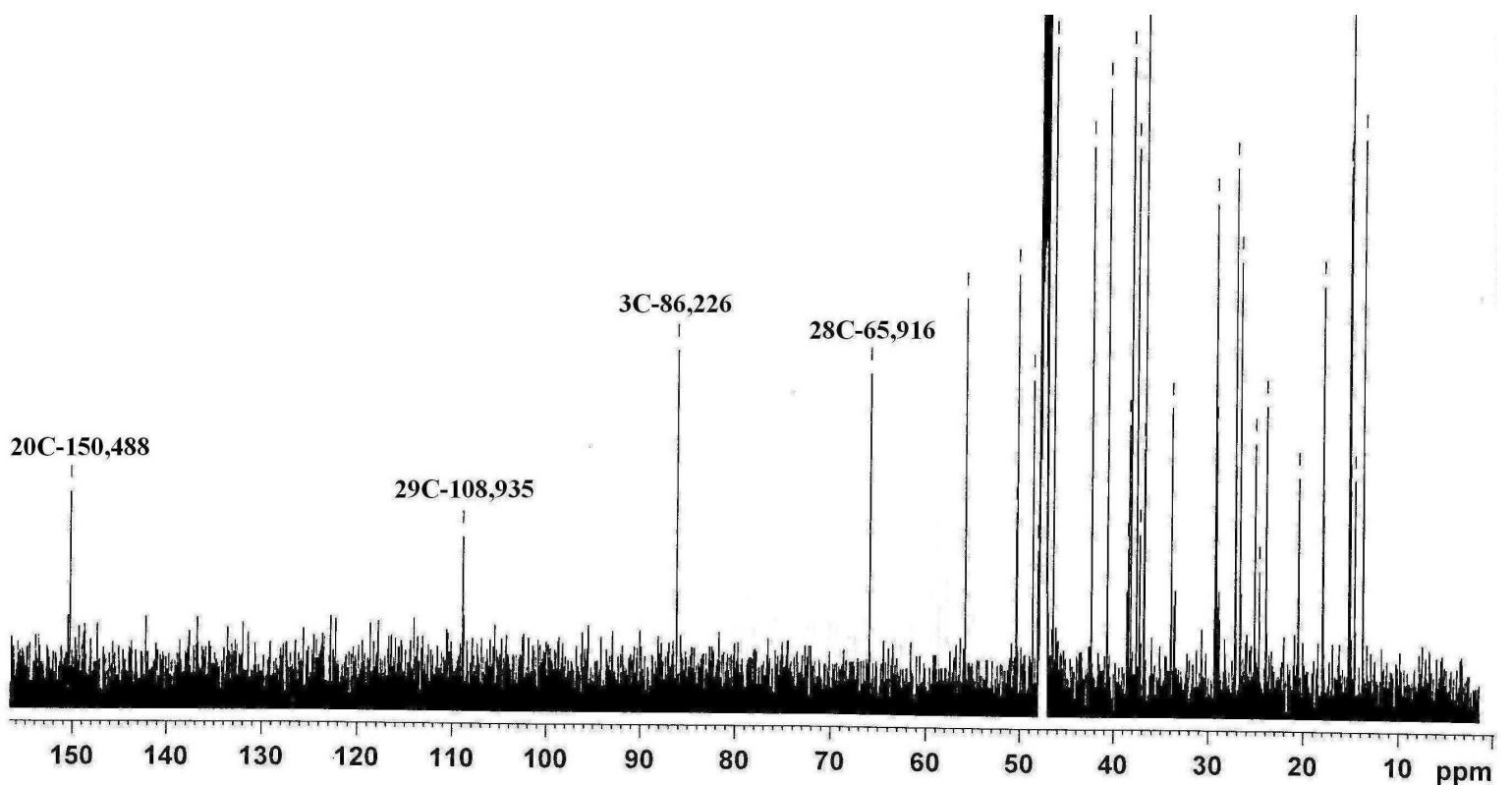

Рис. 4. ЯМР ${ }^{13} \mathrm{C}$-спектр 3,28-дисульфата бетулина

\section{Список литературы}

1. Толстиков Г.А., Флехтер О.Б., Шульц Э.Э., Балтина Л.А., Толстиков А.Г. Бетулин и его производные. Химия и биологическая активность // Химия в интересах устойчивого развития. 2005. №13. С. 1-30.

2. Ле Банг Шон, Каплун А.П., Шпилевский А.А., Андия-Правдивый Ю.Э., Алексеева С.Г., Григорьев В.Б., Швец В.И. Синтез бетулиновой кислоты из бетулина и исследование ее солюбилизации с помощью липосом // Биоорганическая химия. 1998. Т. 24, №10. С. 787-793.

3. Bureeva S., Andia-Pravdivy J., Symon A., Bichucher A., Moskaleva V., Popenko V., Shpak A., Shvets V., Kozlov L., Kaplun A. Selective inhibition of the interaction of $\mathrm{C} 1 \mathrm{q}$ with immunoglobulins and the classical pathway of the complement activation by steroids and triterpenoids sulfates // J. Bioorganic and medicinal chemistry. 2007. Vol. 15, N10. Pp. 3489-3498.

4. Патент 2243233 (РФ). Производные бетулина как ингибиторы комплемента / А.П. Каплун, Ю.Э. АндияПравдивый, С.В. Буреева, Л.В. Козлов, В.И. Швец / 27.12.2004. 
5. Гришковец В.И. Синтез сульфатов тритерпеноидов с использованием комплекса $\mathrm{SO}_{3}$ - диметилсульфоксид // Химия природных соединений. 1999. №1. С. 91-93.

6. Kitajima J., Shindo M., Tanaka Y. Two new triterpenoid sulfates from the leaves of schefflera octophylla // Chem. Pharm. Bull. 1990. Vol. 38, N3. Pp. 714-716.

7. Патент 2340624 (РФ). Способ получения бетулина / В.А. Левданский, А.В. Левданский, Б.Н. Кузнецов / 10.12.2008

8. Гордон А., Форд Р. Спутник химика. М., 1976. 545 с.

9. Джильберт Э.Е. Сульфирование органических соединений. М., 1969. 415 с.

10. Одинокова Л.Э., Ошиток Г.И., Денисенко В.А., Ануфриев В.Ф., Толкач А.М., Уварова Н.И. Гликозилирование бетулина и его ацетатов в присутствии карбоната кадмия // Химия природных соединений. 1984. №2. С. 182-187.

Поступило в редакиию 15 марта 2012 г.

После переработки 22 апреля 2012 г.

Levdansky V.A. ${ }^{1,2}$, Levdansky A.V. ${ }^{l}$, Kuznetsov B.N. ${ }^{1,2 *}$ SULFATION OF BETULIN WITH CHLOROSULFONIC ACID IN DIMETHYLFORMAMIDE AND DIOXANE

${ }^{1}$ Institute of Chemistry and Chemical Technology SB RAS, K. Marx str., 42, Krasnoyarsk 660049 (Russia),

e-mail:inm@icct.ru

${ }^{2}$ Siberian Federal University, pr. Svobodny, 79, Krasnoyarsk, 660041 (Russia)

It was established, that the reaction of sulfation of betulin by chlorosulfonic acid in dioxane or dimethylformamide proceeds in homogeneous medium at temperature $40-60^{\circ} \mathrm{C}$. It was shown that for complete etherification of betilin to betulin 3,28-disulfat 4-5 hours are necessary. Betilin disulfat was obtained in the form of sodium salt.

Keywords: betulin, sulfation, chlorosulfonic acid, 1,4-dioxane, N,N-dimethylformamide, betulin 3,28-disulfate.

\section{References}

1. Tolstikov G.A., Flekhter O.B., Shul'ts E.E., Baltina L.A., Tolstikov A.G. Khimiia v interesakh ustoichivogo razvitiia, 2005, no. 13, pp. 1-30. (in Russ.).

2. Le Bang Shon., Kaplun A.P., Shpilevskii A.A., Andiia-Pravdivyi Iu.E., Alekseeva S.G., Grigor'ev V.B., Shvets V.I. Bioorganicheskaia khimiia, 1998, vol. 24, no. 10, pp. 787-793. (in Russ.).

3. Bureeva S., Andia-Pravdivy J., Symon A., Bichucher A., Moskaleva V., Popenko V., Shpak A., Shvets V., Kozlov L., Kaplun A. J. Bioorganic and medicinal chemistry, 2007, vol. 15, no. 10, pp. 3489-3498. (in Russ.).

4. Patent 2243233 (RU). 27.12.2004. (in Russ.).

5. Grishkovets V.I. Khimiia prirodnykh soedinenii, 1999, no. 1, pp. 91-93. (in Russ.).

6. Kitajima J., Shindo M., Tanaka Y. Chem. Pharm. Bull., 1990, vol. 38, no. 3, pp. 714-716.

7. Patent 2340624 (RU). 10.12.2008. (in Russ.).

8. Gordon A., Ford R. Sputnik khimika. [Satellite chemist]. Moscow, 1976, 545 p. (in Russ.).

9. Dzhil'bert E.E. Sul'firovanie organicheskikh soedinenii. [Sulfonation of organic compounds]. Moscow, 1969,415 p. (in Russ.).

10. Odinokova L.E., Oshitok G.I., Denisenko V.A., Anufriev V.F., Tolkach A.M., Uvarova N.I. Khimiia prirodnykh soedinenii, 1984, no. 2, pp. 182-187. (in Russ.).

Received March 15, 2012

Revised April 22, 2012

\footnotetext{
* Corresponding author.
} 